\title{
On the Nature of Self-Monitoring: Matters of Assessment, Matters of Validity
}

\author{
Mark Snyder and Steve Gangestad \\ University of Minnesota
}

\begin{abstract}
An extensive network of empirical relations has been identified in research on the psychological construct of self-monitoring. Nevertheless, in recent years some concerns have been expressed about the instrument used for the assessment of self-monitoring propensities, the Self-Monitoring Scale. Both the extent to which the measure taps an interpretable and meaningful causal variable and the extent to which the self-monitoring construct provides an appropriate theoretical understanding of this causal variable have been questioned. An examination of reanalyses of studies of self-monitoring, analyses of the internal structure of the Self-Monitoring Scale, and further relevant data suggest that the measure does tap a meaningful and interpretable causal variable with pervasive influences on social behavior, a variable reflected as a general self-monitoring factor. We discuss the evaluation and furthering of the interpretation of this latent causal variable, offer criteria for evaluating alternative measures of self-monitoring, and present a new, 18-item Self-Monitoring Scale.
\end{abstract}

According to theoretical analyses of self-monitoring, people differ in the extent to which they can and do observe and control their expressive behavior and self-presentation (e.g., Snyder, 1979). Individuals high in self-monitoring are thought to regulate their expressive self-presentation for the sake of desired public appearances, and thus be highly responsive to social and interpersonal cues of situationally appropriate performances. Individuals low in self-monitoring are thought to lack either the ability or the motivation to so regulate their expressive self-presentations. Their expressive behaviors, instead, are thought to functionally reflect their own enduring and momentary inner states, including their attitudes, traits, and feelings.

A number of hypotheses-concerning, among others, the determinants of specificity and consistency in social behavior, the origins of linkages between attitudes and action, the dynamics of social interaction, and the nature and consequences of conceptions of self-have followed from these basic initial propositions. Research involving a measure of self-monitoring propensities (the Self-Monitoring Scale; for information on its reliability and validity, see Snyder, 1974) has provided empirical support for these and many more hypotheses about the cognitive, behavioral, and interpersonal consequences of self-monitoring (e.g., Ajzen, Timko, \& White, 1982; Becherer \& Richard, 1978; Caldwell \& O'Reilly, 1982; Danheiser \& Graziano, 1982; Ickes, Layden, \& Barnes, 1978; Krauss, Geller, \& Olson, 1976; Kulik \& Taylor, 1981; Lippa, 1976, 1978; Lutsky, Woodworth,

The research for and the preparation of this article were supported in part by National Science Foundation Grant BNS 82-07632 to Mark Snyder, in part by a National Institute of Mental Health National Research Council postdoctoral traineeship to Steve Gangestad, and in part by a grant from the University of Minnesota Computer Center.

We thank Daryl Bem and Jeffry A. Simpson for their helpful comments on the article.

Correspondence concerning this article should be addressed to Mark Snyder or to Steve Gangestad, Department of Psychology, University of Minnesota, 75 East River Road, Minneapolis, Minnesota 55455.
\& Clayton, 1980; McCann \& Hancock, 1983; Paulhus, 1982; Rarick, Soldow, \& Geizer, 1976; Ross, McFarland, \& Fletcher, 1981; Shaffer, Smith, \& Tomarelli, 1982; Snyder, 1974; Snyder, Berscheid, \& Glick, 1985; Snyder \& Cantor, 1980; Snyder \& Gangestad, 1982; Snyder, Gangestad, \& Simpson, 1983; Snyder \& Kendzierski, 1982a, 1982b; Snyder \& Monson, 1975; Snyder \& Simpson, 1984; Snyder \& Swann, 1976; Snyder \& Tanke, 1976; Tunnell, 1980; Zanna, Olson, \& Fazio, 1980).

More recently, elaboration of the construct has led to its application in yet other domains of social behavior and interpersonal relationships. Some of the domains in which the SelfMonitoring Scale has proven its relevance and applicability are recent and ongoing explorations of the nature of friendships (e.g., Snyder \& Smith, 1986), romantic relationships (e.g., Snyder \& Simpson, 1986), and sexual involvements (e.g., Snyder, Simpson, \& Gangestad, 1986), as well as applications to the psychology of advertising (e.g., Snyder \& DeBono, 1985), personnel selection (e.g., Snyder, Berscheid, \& Matwychuk, 1984), and psychopathology (e.g., Snyder \& Smith, 1985).

Clearly then, over many years of research, a large number of associations between the Self-Monitoring Scale and a wide range of important behavioral criteria have been documented; for reviews of these associations, see Snyder (1979, in press) and Shaw and Costanzo (1982). In a phrase, the measure empirically works. This fact notwithstanding, in recent years some concerns have been expressed about why and how the measure works. Thus, Briggs and Cheek (1986) have stated,

The Self-Monitoring Scale is a popular measure of personality and has served as the centerpiece for a number of published articles. The scale has proved successful in predicting a variety of criteria and has acted to stimulate experimental social psychologists' interest in the measurement of individual differences. The problem is to understand why the scale works. (p. 129)

Of course, one may ask, isn't the obvious answer that the SelfMonitoring Scale works because it measures the differences between individuals explicated by the self-monitoring construct? Or, if it doesn't measure the self-monitoring construct, doesn't 
the scale work at least because it measures meaningful and systematic individual differences implicated in social behavior and interaction? Although these may appear to be the obvious answers, they are, according to Briggs and Cheek as well as others (e.g., Lennox \& Wolfe, 1984), wrong. For, according to these authors, the Self-Monitoring Scale possesses psychometric properties that pose threats to its ability to measure meaningful and interpretable individual differences.

\section{The Self-Monitoring Scale: What Does It Measure?}

Specifically, what are the concerns that have been expressed about the measure of self-monitoring? First, it has been claimed that the Self-Monitoring Scale, whatever it measures, does not validly measure the self-monitoring construct. The tenor of this claim has ranged from the merely suggestive to the unshakably resolute. Thus, Briggs, Cheek, and Buss (1980) have suggested that there "may be a gap between the construct of self-monitoring and its operationalization in the Self-Monitoring Scale" (p. 586). And, Lennox and Wolfe (1984) have asserted that the "measure demonstrably lacks fidelity to the construct [of selfmonitoring]" (p. 1350).

Second, it has been claimed that the Self-Monitoring Scale not only does not measure the construct of self-monitoring, but also may not be a good measure of anything at all-at least anything that is interpretable or meaningful. Thus, Briggs et al. (1980) have suggested, for instance, that "subjects labeled high self-monitors in one study might be different from those labeled high self-monitors in another study" (p. 684). And, Lennox and Wolfe (1984) have stated, in no uncertain terms, that "the total score on [the] scale tends to defy interpretation; it is impossible to determine what the scale as a whole might be measuring" ( $p$. 1350 ), and that the "measure . . . exhibits fundamental psychometric weaknesses" (p. 1350).

It may seem that any measure that not only fails to tap the latent construct that it is intended to tap, but also fails to tap anything else, should be a rather worthless tool for purposes of doing research to find associations with important aspects of social behavior. But, as we have noted, a very large number of associations have been found to exist between the Self-Monitoring Scale and behavioral criterion variables. If the measure has "fundamental psychometric weaknesses," why and how does it work as well as it does? Those who have raised concerns about the psychometric soundness of the measure have provided one answer to this question. They claim that the measure has associations in the wide-ranging domains that it does because, in fact, it measures not one person variable but, rather, multiple person variables (e.g., Briggs \& Cheek, 1986). As a result, it is claimed, the measure has associations with behavioral criterion variables related to each of the multiple aspects of social behavior that the Self-Monitoring Scale taps (none of which, incidentally, can be identified as self-monitoring). Thus, they claim, the number and range of effects the Self-Monitoring Scale achieves are achieved illicitly.

What are we to make of these concerns expressed about the Self-Monitoring Scale? Does the measure have fundamental psychometric weaknesses? Does the measure achieve its effects illicitly by tapping not a single entity but rather multiple aspects of individual differences simultaneously? In the present article, we address these questions about the Self-Monitoring Scale. Al- though we explicitly deal with specific issues about the SelfMonitoring Scale, we will implicitly speak also to general concerns in the development and use of measures of individual differences in building psychological theory. It is our hope that discussion of issues surrounding the Self-Monitoring Scale will contribute meaningfully to understanding fundamental issues in personality.

\section{Factor Analytic Investigations and Their Implications}

Lennox and Wolfe (1984) claimed that if the Self-Monitoring Scale measures something, this something is uninterpretable (and thus presumably unmeaningful) due to "fundamental psychometric weaknesses" (p. 1350). What are these purported fundamental psychometric weaknesses? How would they render total scores on the measure uninterpretable and unmeaningful? The major claims about psychometric weaknesses of the Self-Monitoring Scale have been based on interpretations of factor-analytic investigations. It is now well established that factor analysis of the Self-Monitoring Scale yields multiple factors-generally three (e.g., Briggs et al., 1980), although as few as two (Sparacino et al., 1983) and as many as four (Gabrenya \& Arkin, 1980) have been reported. Our own scree test (Cattell, 1966) of the eigenvalues on a large college sample $(N=$ 1918 ) clearly suggested three reliable factors (Gangestad \& Snyder, 1985b).

Rotated factor structures of three factor solutions (e.g., Briggs et al., 1980) have reliably identified three item-content clusters. A first cluster (which we call expressive self-control) concerns the ability to actively control expressive behavior, for example, "I would probably make a good actor" (keyed true) and "I can look anyone in the eye and tell a lie with a straight face (if for a right end)" (true). A second cluster (social stage presence) concerns the propensity to perform in social situations and attract social attention to oneself, for example, "In a group of people I am rarely the center of attention" (false) and "At a party I let others keep the jokes and stories going" (false). A third cluster (other-directed self-presentation) concerns displaying what others expect one to display in social situations, for example, "I may deceive people by being friendly when I really dislike them" (true) and "I guess I put on a show to impress or entertain people" (true).

How might factor-analytic studies indicate psychometric weaknesses that threaten the coherence and meaningfulness of the Self-Monitoring Scale? Briggs and Cheek (1986) have provided the clearest statement of the concerns that follow from factor-analytic studies (although similar concerns are at least implicit in Briggs et al., 1980; Cheek \& Briggs, 1981; and Lennox \& Wolfe, 1984). A single scale, Briggs and Cheek (1986) asserted, should measure a single individual difference or person variable. Quoting McNemar (1946): "Measurement implies that one characteristic at a time is being quantified" (p. 268). The fact that factor-analytic investigations find that multiple person variables account for the interrelations between selfmonitoring items, Briggs and Cheek claim, raises the strong possibility that the items do not measure a single person variable.

What are the problems that follow from use of a measure that does not tap a single person variable? First, the total scores are rendered uninterpretable (Briggs et al., 1980; Lennox \& Wolfe, 
1984). If a measure taps three nearly orthogonal person variables, then total scores represent linear composites of three nearly orthogonal components. Thus, the same total score may represent for one person a very different pattern of factor scores than it represents for another person. Why, these authors ask, should these two persons' responses be represented by the same score? Second, if multiple person variables are tapped by a single measure, the relations that the measure possesses with external criterion variables may be attributable to different person variables; that is, they may be causally heterogeneous. Thus, one factor may account for the relations found in one set of studies, a second factor for another set, and the third factor for yet a third set. Clearly, if the relations a measure possesses are causally heterogeneous, they should not be systematized or explained in a theoretical framework that asserts that a single person variable accounts for them.

We do not take issue with the premise that a single measure should, to the extent possible, measure a single person variable or entity. The problems that ensue when a measure taps multiple person variables to approximately equal extent and when the variance in a measure is not to some substantial extent attributable to a single person variable, we agree, are genuine problems. We do, however, take issue with the claim that factoranalytic investigations have yet demonstrated that the variance in the Self-Monitoring Scale is not, to any substantial extent, attributable to a single person variable that is conceptually meaningful. Indeed, we have pursued a line of research that offers an alternative perspective on the factor-analytic investigation of the Self-Monitoring Scale, one that postulates that a single person variable does underlie a substantial amount of the variance in the measure.

\section{Interpreting the Implications of Factor Analysis}

Typically, factor-analytic investigations have focused on rotated factor structures (e.g., Briggs et al., 1980; Furnham \& Capon, 1983; Gabrenya \& Arkin, 1980; Lennox \& Wolfe, 1984; Nowack \& Kammer, 1984; Riggio \& Friedman, 1982; Sparacino et al., 1983). We, however, consider it most informative to begin with the unrotated factor structure. For, if some major portion of the variance in the full Self-Monitoring Scale does reflect a single latent person variable or entity, that entity should be reflected as a general factor, a factor on which most of the items positively load. Given the manner in which the Self-Monitoring Scale was constructed (items chosen to tap coherently a hypothesized latent variable), this general factor, if it exists, should naturally be reflected as the first unrotated factor (Rummel, 1970).

The first unrotated factor emerging from a factor analysis of the Self-Monitoring Scale is indeed a factor on which most of the items positively load. In our own factor analysis of the responses of 1,918 college students, 24 of the 25 items had positive loadings on this first unrotated factor; 18 of these 24 items had loadings of +.15 or greater (Gangestad \& Snyder, 1985b). Clearly, this first unrotated factor must correlate highly with the total Self-Monitoring Scale. And, given that the second and third unrotated factors are bipolar (that is, some items load positively, whereas others load negatively), these factors do not correlate highly with the total Self-Monitoring Scale. If there is some single meaningful person variable to which a substantial amount of the total score variance is attributable, then that variable should closely correspond to the first unrotated factor.

Of course, we cannot consider the fact that a general factor exists as, in and of itself, justification that this general factor closely corresponds to a single meaningful person variable. Indeed, others who have conducted factor-analytic studies may already have dismissed, even if implicitly, the general factor's possible meaningfulness. They may simply have felt it justified, on a priori grounds, to regard factors rotated to simple structure as the interpretable, meaningful, and "real" sources of variation underlying the Self-Monitoring Scale items. Accordingly, they may have dismissed the unrotated factor structure as an arbitrary, and thus psychologically meaningless, result of the real coherences (i.e., rotated factors) in the self-monitoring items.

In fact, justifications for regarding rotated factors as real and unrotated ones as arbitrary have been proposed. It is often assumed (e.g., Cattell, 1978) that, if a set of overt variables has multiple causative influences, then any one underlying influence substantially affects only a portion of them. It is also often assumed (e.g., Thurstone, 1947) that any one overt variable is likely to be influenced substantially by only one real underlying variable. To the extent that these assumptions are correct, the rotated factor structure will indeed reveal the real underlying sources of variation.

Whether or not one accepts these assumptions as generally appropriate, one must recognize inferential risks associated with automatically interpreting the rotated factor structure as that containing the real, nonarbitrary underlying sources of variance. In fact, leading experts, including many proponents of simple structure rotation (e.g., Cattell, 1978; Eysenck, 1950; Guilford \& Zimmerman, 1963; Overall, 1964), have discussed these risks. In the present context, Cattell's (1978) remarks are most instructive. He has noted that the assumption that any real source of influence substantially affects only a subset of the overt variables is not likely to hold if the variables one factor analyzes are not expected to be widely heterogeneous. Thus,

simple structure requires a foresighted choice of the sample of variables. It is obviously absurd to expect to get any determinate rotation of a certain factor $X$ if we have chosen the variables in the study such that probably all of them will have some significant loading on X. (Cattell, 1978, p. 112)

This statement has obvious implications for the present case. The Self-Monitoring Scale, like any other rationally derived and empirically refined measure (e.g., Nunnally, 1967), was constructed to meet precisely these conditions (Snyder, 1974).

Thus, it is true that the existence of a factor with general positive loadings does not in itself vindicate the meaningfulness of a general factor underlying responses to the Self-Monitoring Scale. However, it is also true that the lack of a general factor after rotation to simple structure does not justify the conclusion that a general factor is unmeaningful. To further address the possibility that a single entity can account for a substantial portion of the variance in self-monitoring scores, we next examine relations of the Self-Monitoring Scale with external social behavioral variables.

\section{External Relations of the Measure and the Factors}

A major concern about the possibility that the Self-Monitoring Scale measures multiple individual differences is the ensu- 
ing possibility that the associations observed in self-monitoring studies are causally heterogeneous. That is, perhaps some associations are attributable to one factor, others to a second factor, and still others to a third factor. There do exist some indications in the literature of differential effects of the factors (e.g., Cheek, 1982; Penner \& Wymer, 1983; Sypher \& Sypher, 1983), and we will discuss these studies later. Let us now, however, consider a set of 15 studies that we have reanalyzed by means of the factors, as well as the full measure, in light of expressed concerns. These studies cover a wide range of social phenomena, and include studies within the cognitive, behavioral, and interpersonal domains (see Table 1).

Was it the case that the effects in these studies were due to one or other factor? Clearly not. In general, the factors tended to be associated similarly with the criterion variables. Moreover, almost as a rule, the full Self-Monitoring Scale outperformed all of the factors-in spite of the fact that each of the factors possesses internal consistency similar to that of the full measure (Briggs et al., 1980). In only 4 out of 19 comparisons in these 15 studies was any factor more related to the criterion variable than the full scale. ${ }^{1}$ Clearly then, these studies, at least, are very consistent with the conjecture that the general self-monitoring factor that can be found in the factor space, and that is highly related to full scale scores, accounts for many associations the scale possesses. Indeed, the most parsimonious explanation of these studies is that it is the general factor that makes the scale work.

Nevertheless, parsimony aside, an alternative must be considered. Perhaps the rotated factors are the "real" person variables underlying the total measure, and each of the factors has independent and additive effects on the criterion variables in the studies we examined. This may seem an unlikely possibility, given that it requires multiple parallel effects of what are claimed to be very distinct and different person variables; but it $i$ a possibility. We now turn to consider further evidence that the general factor is a meaningful underlying causal variable.

\section{Nature of the General Factor}

Recently, we reported extensive taxometric analyses of the internal structure of the self-monitoring items; these analyses suggested that a major source of variation in the responses to the Self-Monitoring Scale is a discrete or quasi-discrete entity, as opposed to a normally distributed continuous variable (Gangestad \& Snyder, 1985b). This postulated causal entity accounts for over one half of the reliable variance in full Self-Monitoring Scale scores, and in fact appears to be reflected as the first unrotated factor in a factor analysis of the items. Furthermore, reanalyses of a sample of self-monitoring studies in light of these findings provides evidence that much of the criterionoriented validity of the Self-Monitoring Scale is attributable to this causal entity (Gangestad \& Snyder, 1985b). Indeed, a measure of the causal entity performed, on average, as well in these studies as did the full Self-Monitoring Scale itself and better than each of the rotated factors. In essence, we claimed that what in large part makes the Self-Monitoring Scale work is the existence of strong effects of this latent causal entity that is reflected in the same region of the factor space as the general selfmonitoring factor.

Of course, it is natural to ask what this postulated discrete causal entity might be. This question has been addressed in further speculation and investigation. Indeed, evidence is now mounting that the causal variable corresponding to the general factor has a biological genetic basis (Dworkin, 1977; Gangestad, 1984; Gangestad \& Snyder, 1985a). Specifically, it has been estimated that monozygotic (MZ) twins are nearly always, if not always, concordant on this latent factor, whereas dizygotic (DZ) twins are concordant at better than a chance rate, but at a rate substantially less than $\mathrm{MZ}$ twins.

Presently, we wish to present further data from this twin study relevant to assess whether the Self-Monitoring Scale taps some single person variable. Let us begin with a consideration of the intraclass correlations between MZ twins (149 pairs) on each of the rotated factors. These correlations reflect the operation of any influences (environmental, genetic, or combinational) that create greater similarity between $\mathrm{MZ}$ twins than between randomly paired individuals. The $\mathrm{MZ}$ correlations of $.60, .56$, and .34 for the factors of expressive self-control, social stage presence, and other-directed self-presentation, respectively, indicate that in fact, for each of these factors, there do exist these influences.

But now, let us further question the nature and relation of these influences. On the one hand, it is possible that these influences underlying the three rotated factors are wholly separate and distinct. If the rotated factors do not have a common underlying substrate, then it will be the case that these genetic and environmental influences are distinct. Alternatively, however, it is possible that the genetic or environmental influences on these factors are overlapping to a substantial degree. That is, the rotated factors may share, perhaps even to a substantial extent, a common genetic or environmental influence. In fact, we can assess these possibilities. If the causal influences on rotated factors are distinct, then the similarity of $\mathrm{MZ}$ twins on an additive composite of the three factors will be less than that for the factors themselves. If, on the other hand, the factors share some causal influence, the similarity of $\mathrm{MZ}$ twins on a composite of the three factors may exceed that for the factors themselves. Did

\footnotetext{
${ }^{1}$ Of course, given sampling variability, we should expect on occasion one or other factor to outperform the full measure, even if the actual effect size in the population was always greatest for the full measure. In this light, it is interesting to note that three of the four studies in which a factor outperformed the full measure were studies with the smallest sample sizes, and thus studies for which sampling variability should be greatest. We may also note that for two of the same four comparisons, a second comparison in the same study demonstrated greater effect size for the full measure than for the factors.

We also may note that we do not expect all of the factors to perform identically well. The three rotated factors all correlate positively with the general factor, but not equally: expressive self-control, $r=.6$; social stage presence, $r=.5$; other-directed self-presentation, $r=.3$ (Gangestad $\&$ Snyder, $1985 \mathrm{~b}$ ). The relative ability of the factors to predict the criterion variables in the studies we reanalyzed do, in fact, correspond to their relative correlations with the general factor.

Although samples for several of the studies we reanalyzed were selected for extreme scores on the Self-Monitoring Scale, a procedure that generates within these samples increased correlation between individual factors, samples in six studies were unselected and in another two studies represented the full range of self-monitoring scores. For 9 out of 10 comparisons in these studies, the full measure outperformed all factors.
} 
Table 1

Assessment of the General Self-Monitoring Factor: Comparison of the Full Self-Monitoring Scale With the Rotated Factors

\begin{tabular}{|c|c|c|c|c|}
\hline Investigation & $\begin{array}{c}\text { Full Self- } \\
\text { Monitoring Scale }\end{array}$ & $\begin{array}{l}\text { Social stage } \\
\text { presence factor }\end{array}$ & $\begin{array}{l}\text { Other-directed self- } \\
\text { presentation factor }\end{array}$ & $\begin{array}{l}\text { Expressive self- } \\
\text { control factor }\end{array}$ \\
\hline \multicolumn{5}{|l|}{ Snyder \& Cantor (1980) } \\
\hline \multicolumn{5}{|l|}{ Investigation 2} \\
\hline$m F(4,53)$ & 2.83 & 2.44 & 1.36 & 1.03 \\
\hline$F(1,56)$ & 8.29 & 0.01 & 1.10 & 0.51 \\
\hline \multicolumn{5}{|l|}{ Snyder \& Gangestad (1982) } \\
\hline Investigation $1: F(1,117)$ & 11.49 & 4.90 & 6.70 & 3.91 \\
\hline \multicolumn{5}{|l|}{ Investigation 2} \\
\hline$F(1, \infty)$ & 5.89 & 2.61 & 2.61 & 3.91 \\
\hline$F(1, \infty)$ & 4.24 & 6.09 & 0.00 & 2.30 \\
\hline \multicolumn{5}{|l|}{ Snyder \& Kendzierski (1982b) } \\
\hline Investigation 1: $F(1, \infty)$ & 11.90 & 8.51 & 5.89 & 5.21 \\
\hline \multicolumn{5}{|l|}{ Snyder, Gangestad, \& Simpson (1983) } \\
\hline Investigation $1: t(28)$ & 3.93 & 1.47 & 2.93 & 3.98 \\
\hline Investigation $2: t(58)$ & 2.53 & 0.46 & 0.95 & 1.83 \\
\hline \multicolumn{5}{|l|}{ Snyder \& Simpson (1984) } \\
\hline Investigation $1: t(30)$ & 7.16 & 3.18 & 3.61 & 4.83 \\
\hline \multicolumn{5}{|l|}{ Investigation 2} \\
\hline$t(28)$ & 2.92 & 2.70 & 1.33 & 1.73 \\
\hline$t(28)$ & 2.61 & 3.08 & 1.66 & 1.88 \\
\hline \multicolumn{5}{|l|}{ Investigation 3} \\
\hline$t(76)$ & 2.28 & 1.63 & 1.10 & 1.63 \\
\hline$t(80)$ & 2.44 & 2.02 & 1.03 & 1.84 \\
\hline Investigation $4: t(253)$ & 2.60 & 1.62 & 0.48 & 1.63 \\
\hline \multicolumn{5}{|l|}{ Snyder, Simpson, \& Gangestad (1986) } \\
\hline$t(143)$ & 6.03 & 3.05 & 2.82 & 5.13 \\
\hline \multicolumn{5}{|l|}{ Snyder, Berscheid, \& Glick (1985) } \\
\hline Investigation $1: t(37)$ & 2.98 & 1.98 & 2.90 & 1.38 \\
\hline Investigation $2: t(30)$ & 2.68 & 3.61 & 1.98 & 0.72 \\
\hline \multicolumn{5}{|l|}{ Snyder \& Smith (1985) } \\
\hline Investigation $1: F(1,198)$ & 26.31 & 12.16 & 14.77 & 10,28 \\
\hline Investigation $2: F(1,70)$ & 8.83 & 0.17 & 1.60 & 1.23 \\
\hline
\end{tabular}

Note. All effects within a single study are in the same direction.

the similarity of twins on the general factor (which is a weighted composite of items from all three rotated factors) exceed that of the rotated factors? Indeed, it did. The intraclass correlation for this general factor was .64 , which is significantly larger than those of the rotated factors (all $t s>2, p<.05$; Gangestad, 1985). ${ }^{2}$

What do these analyses, then, show? They show that the rotated factors do indeed appear to share some common genetic influence. They are not etiologically distinct. Moreover, this common genetic factor appears to correspond closely to a general factor that is the first unrotated factor. Given that this general factor generally outperformed all three rotated factors in our reanalyses of 15 self-monitoring studies, it is our view that the causal influence contributing variance to all three factors is largely responsible for the relations we observed in these studies. We believe that the evidence not only invites, but also encourages, one to adopt this view. In any case, however, surely the evidence does not now permit one to dismiss this view.

\section{Links Between the Factors and Other Variables}

We have claimed that more than one half of the reliable variance in the full Self-Monitoring Scale is attributable to a single causal influence and that if our reanalyses are any indication, a sizeable number of the associations the measure possesses are attributable to this factor. Still, although we believe the variance attributable to this single latent variable is substantial, perhaps $40 \%$ of the reliable variance in the measure is not attributable to this variable (Gangestad \& Snyder, 1985b). What are the implications of this fact?

Even though one may conclude, as we do, that all three rotated factors possess variance attributable to a common influence, one should also recognize that the rotated factors do emerge, and that they emerge precisely because the items on the Self-Monitoring Scale share systematic variance with each other that is not attributable to this common influence (see

\footnotetext{
${ }^{2} \mathrm{~A}$ factor analysis of the monozygotic (MZ) cross-twin correlations (which reflect covariance due only to family influences, environmental or genetic) yielded two factors. The first factor closely resembled the first unrotated factor of the large college sample (factor congruence $=$ .91), Furthermore, varimax rotation to simple structure did not change substantially the factor structure. Indeed, the first rotated factor also closely resembled the first unrotated factor of the large college sample (factor congruence $=.91$ ). This result shows that by varying the influences one allows to contribute to covariation, one changes the factor structure. When only family influences are allowed, the general factor emerges in the rotated as well as unrotated factor structures. The fact that the dizygotic (DZ) twin intraclass correlation on the general factor was only .19 indicates that the family influence is substantially genetic in nature.
} 
Gangestad \& Snyder, 1985b, for a fuller discussion of this point). The rotated factors, then, possess variance independent of the general self-monitoring factor, and independent of one another also. Some of this variance is reflected in full scale scores, and it is probably the case that the factors on average contribute from $10 \%$ to $15 \%$ reliable variance to total scale score, independent of the general common causal influence.

It follows that the rotated factors may possess moderate amounts of psychologically meaningful variance with certain criterion variables that is independent of the general self-monitoring factor. Thus, for instance, perhaps the expressive selfcontrol factor is related to control of expressive behavior in posed conditions, and the social stage presence factor to the spontaneous control of expressive behavior (e.g., Riggio \& Friedman, 1982; Siegman \& Reynolds, 1983). Or, perhaps only the expressive self-control factor is related to ability to predict the impression one is making on an audience (Tobey \& Tunnell, 1981; see Cheek, 1982; Nowack \& Kammer, 1984; Penner \& Wymer, 1983; Riggio \& Friedman, 1983; Sypher \& Sypher, 1983 , for other claims of differential relatedness of the factors to external variables).

Because it is possible that the factors do possess external relations independently of the general factor, and because these relations may contribute to a better understanding of self-monitoring phenomena, we encourage researchers, in addition to analyzing their studies using the Self-Monitoring Scale, to examine the relations of the rotated factors to their criterion variables. If the factors do not correlate with the criterion variable in the pattern expected if the general factor had accounted for the relations (e.g., if one factor correlates substantially and the other two do not at all), then it is likely that any relation the full scale possesses with the criterion variable is not largely attributable to the general factor.

When researchers evaluate results for differential effects of the rotated factors, they should use appropriate inferential statistics and methodological standards. In a distressingly large number of instances, researchers have fallaciously reasoned that differential effects do exist. Specifically, researchers have claimed or implied that, because one factor is significantly related to a criterion variable in their study and a second factor is not significantly related to the same variable, the two factors possess different relations to the criterion variable (e.g., Riggio \& Friedman, 1983; Siegman \& Reynolds, 1983; Tobey \& Tunnell, 1981). Thus, for instance, Tobey and Tunnell argued that because the expressive self-control factor correlated significantly with ability to predict one's impression upon another $(r=.25, p<.05)$, whereas the social stage presence factor and the other-directed self-presentation factor did not $(r s=-.01$, -.03 ), the three factors possess different relations with ability to predict one's impression. This reasoning is, of course, flawed. To demonstrate convincingly that two factors are differentially related to a third variable, one should demonstrate that it is very unlikely that the observed sample correlations of the two factors with the third variable would differ as much as they do if they were precisely identical in the population (e.g., Hays, 1981). In the study by Tobey and Tunnell, in fact, one could expect a difference between the correlations of the factors with the criterion variable as large as the difference observed, even if the factors all possessed identical relations with the criterion variable, with probability greater than the standard .05 crite- rion level (for the difference between the two most extreme correlations, $t(45)=1.79, n s$; adjusting for experimentwise error, we could expect a $t$ statistic of this size with even greater probability).

Once again, however, we do not deny that differential relations of the factors with other variables do exist and, with appropriate methodologies, can be-and have been-detected. These differential relations suggest that although many relations that the Self-Monitoring Scale possesses are attributable to a single person variable, some relations may be attributable to minor sources of variation in the Self-Monitoring Scale, in dependent of this single variable. Simply stated, the evidence indicates that the general self-monitoring factor reflects a causal entity that accounts for the relations between the Self-Monitoring Scale and a wide range of external variables, and at the same time there exists variance in the rotated factors that is independent of this causal entity and related to certain external variables. Therefore, one important goal for further research will be the specification and delineation of the domains and implications of each set of relations. Although it may be too early to know for certain, it very well may be that there will emerge separate domains, in some of which the general self-monitoring factor will perform as the best predictor and in others of which individual factors will serve as the best predictors of particular criterion variables.

The sharpest concerns over differential factor relations have emerged in the context of the factors' relations with measures to which the full scale is not necessarily expected and does not relate. Thus, for instance, we know of no theoretical reason to expect self-monitoring to be substantially related to trait anxiety. And in fact, the full Self-Monitoring Scale relates trivially to a measure of trait anxiety, $r=.05$ (Cheek \& Briggs, 1981). Yet, if one examines the factor correlations, one can note that trait anxiety correlates negatively with the social stage presence factor but positively with the other-directed self-presentation factor. Similarly, a measure of social self-confidence correlates positively with the social stage presence factor but negatively with the other-directed self-presentation factor. Based on such findings, Briggs and Cheek (1986) have asked how two content domains can correlate with a third variable in opposite directions and still tap the same underlying construct. Their apparent answer to this question (an answer also offered by Briggs et al., 1980, Cheek \& Briggs, 1981, and Lennox \& Wolfe, 1984): They cannot.

This answer is simply wrong. In fact, the issue of factor correlations with third variables is -in the context of whether there exists a unitary causal entity underlying all factors-to a large extent a red herring. Consider an empirical example. Specifically, consider three measures from Jackson's (1967) Personality Research Form: nurturance, the extent to which the respondent gives assistance and comfort to others; succorance, the extent to which the respondent seeks sympathy and reassurance from others; and endurance, the extent to which the respondent perseveres. Among North American college students, each of the first two measures, nurturance and succorance, correlates moderately with the third, endurance, but in opposite directions (Jackson, 1967). Nurturance correlates moderately positively with endurance (approximately +.25 ), and succorance correlates moderately negatively with endurance (approximately -.25 ). 
Using the reasoning of those who have faulted the Self-Monitoring Scale for the correlations of its rotated factors with other personality variables, one would conclude that nurturance and succorance could not validly tap a common latent construct. Moreover, one would conclude that these two measures could not be combined as factors of a larger measure that validly taps some latent construct that is readily interpretable and psychologically meaningful. This reasoning, not incidentally, would also force one to conclude that the variable of biological sex is not readily interpretable and psychologically meaningful. For, both nurturance and succorance validly tap biological sex, each correlating with it approximately .4. But, we do not know of anyone who would believe that biological sex is not a variable that is, in some manner, importantly involved in individual differences.

A close examination of the mathematics of this example reveals that there is nothing odd about it. Given that nurturance and succorance correlate .4 with biological sex, they each share approximately $16 \%$ of their variance with biological sex. Furthermore, at least $80 \%$ of the variance in each measure is reliable variance (Jackson, 1967). This being so, the measures of nurturance and succorance contain $64 \%$ reliable variance that is orthogonal to biological sex. Given that each measure correlates +.25 or -.25 with endurance, each measure shares approximately $6 \%$ (.25 squared) of its variance with endurance. Now, why should one be surprised to find that less than $10 \%$ of the reliable variance of each measure is shared with some third variable orthogonal to sex (i.e., endurance), even if the relations are in opposite directions? The mathematics of this example tells us that this situation is easily possible. There is more than sufficient reliable variance in each measure orthogonal to biological sex $(64 \%)$ to accommodate the less than $10 \%$ that is related to a third variable in opposite ways.

The case of the factors underlying self-monitoring is not substantially different from this illustrative case involving biological sex. Cheek and Briggs (1981) have found a measure of trait anxiety to correlate +.26 with other-directed self-presentation, and -.28 with social stage presence. We estimate the correlation between other-directed self-presentation and the latent selfmonitoring causal variable to be approximately +.3 , and the correlation between social stage presence and the latent selfmonitoring causal variable to be approximately +.5 (Gangestad \& Snyder, 1985a). Furthermore, the variance within each of the factors is $65 \%-70 \%$ reliable (Briggs et al., 1980). Therefore, we can calculate that there is sufficient reliable variance in the two factors that is orthogonal to the general self-monitoring factor (at least $40 \%$ ) to accommodate the variance (less than $8 \%$ ) that is related in opposite ways to trait anxiety.

Consider a more extreme case. Cheek and Briggs (1981) reported that a measure of social self-confidence (the Texas Social Behavior Inventory; TSBI) correlates +.65 with the social stage presence factor, but -.32 with the other-directed self-presentation factor. A measure of the general self-monitoring factor (the full Self-Monitoring Scale) correlates +.27 with the TSBI. This means that the social stage presence and other-directed self-presentation factors share about $35 \%$ and $20 \%$ of their variance, respectively, with the TSBI, independent of their relation to the general self-monitoring factor. Both of these values are possible, because once again, each factor possesses at least $40 \%$ reliable variance, independent of the general self-monitoring factor.
These calculations do indicate, incidentally, that a substantial portion of the reliable variance in the social stage presence and the other-directed self-presentation factors that is not attributable to the general self-monitoring factor apparently is also attributable to a common source, which can be characterized as social self-confidence. Unlike the relations these two factors have with the general self-monitoring factor, however, the relations they possess with social self-confidence are in opposite directions. In the full scale, then, the component of social selfconfidence in the social stage presence factor is counterbalanced by the component of social self-confidence in the other-directed self-presentation factor, with the result that the full scale correlates only moderately with social self-confidence.

\section{A House Divided Unto Itself?}

In their article, Briggs and Cheek (1986) appear to suggest that this "concealing" of the variance components related to social self-confidence (as well as other measures, such as selfesteem) is illicit:

The apparently inconsequential correlations between the SelfMonitoring Scale and other personality measures are misleading insofar as they conceal contradictory and often rather substantial relationships between the components of self-monitoring and these same personality variables, . . . The Self-Monitoring Scale is 'a house divided unto itself.' (p. 123)

(Lennox \& Wolfe, 1984, make similar remarks.) We do not know in what sense Briggs and Cheek see the small-to-moderate correlations of the Self-Monitoring Scale as misleading, and thus we can only state why we believe there is nothing illicit about summing across all three factors to measure the causal influence reflected in the general factor.

Consider a hypothetical situation. Suppose two variables, $\mathrm{X}$ and $Y$, correlate with a causal variable, Theta, .5. $X$ and $Y$ have equal total variance, and variance components in $X$ and $Y$ other than that attributable to Theta are independent from one another (indeed, let us for simplicity's sake assume that they reflect nonvalid error). If we wish to measure Theta, we can sum $\mathrm{X}$ and $\mathrm{Y}$ to obtain a measure of Theta with greater validity than that of either $\mathrm{X}$ or $\mathrm{Y}$ alone; it can be shown through simple psychometric derivation that the sum of $X$ and $Y$ (let us call it Scale XY) will correlate with Theta, .63 . This, presumably, is how Briggs and Cheek (1986) would have us measure person variables.

Now consider a second hypothetical situation. Suppose $V$ and $\mathrm{W}$ correlate with the causal variable, Theta, .45 . $\mathrm{V}$ and $\mathrm{W}$ have equal variance, but unlike $\mathrm{X}$ and $\mathrm{Y}, \mathrm{V}$ and $\mathrm{W}$ do share a second component. $\mathrm{V}$ and $\mathrm{W}$ correlate with a causal variable (orthogonal to Theta), Zeta, but in opposite directions: +.45 and -.45 , respectively. Can we sum $\mathrm{V}$ and $\mathrm{W}$ to measure Theta with greater validity than either $\mathrm{V}$ or $\mathrm{W}$ alone? The correlation between the sum of $\mathrm{V}$ and $\mathrm{W}$ (Scale VW) would certainly suggest that we can; it can be shown (once again, through psychometric derivation) that, as a measure of Theta, Scale VW will have a validity coefficient of .64, comparable to that of Scale XY.

But wait. Doesn't the fact that the two components correlate in opposite directions with Zeta complicate matters (perhaps even mislead us into thinking Scale VW is a good measure of Theta)? Isn't Scale VW "a house divided unto itself"? An ex- 
amination of the correlation between Scale VW and Zeta shows that it has a correlation with Zeta identical to that of Scale $X Y-z e r o$. Thus, the scales are identical in the extent to which Zeta is a nuisance variable. But perhaps the fact that the two components correlate in different directions (a fact that is "concealed" in the sum) means that there is an increased possibility that in some samples, Scale VW will correlate strongly positively with Zeta, whereas in other samples, Scale VW will correlate strongly negatively with Zeta. Once again, however, further thought indicates that in this respect, too, Scale VW does not differ from Scale XY. For a given sample size, a correlation of zero has a given sampling variability; both Scale VW and Scale $X Y$ correlate zero with Zeta, and these correlations thus have identical sampling variability.

One further possible objection, however, is that two persons who obtain identical scores on Scale VW, one by scoring high on $\mathrm{V}$ and low on $\mathrm{W}$, the other low on $\mathrm{V}$ and high on $\mathrm{W}$, will be different psychologically. They will be expected to differ on Zeta, and in a predictable fashion. A similar situation does not exist with Scale XY. But, we ask, how does this complicate matters? Of course the two persons with identical scores but different patterns of response will be expected to differ psychologically, but not in ways that are inconsistent with the purpose of the measure. The two individuals will differ with respect to Zeta, which Scale VW is not meant to measure (it correlates zero with Zeta). Rather, VW is a measure of Theta. And thus, what is important is that the two individuals in this example with identical scores on Scale VW are in fact expected to have similar standing on Theta. ${ }^{3}$

In sum, Briggs and Cheek (1986), as well as others (e.g., Lennox \& Wolfe, 1984), would have us reject Scale VW as a measure of Theta. We, in contrast, see no reason why Scale VW is not just as good a measure of Theta as is Scale XY. Indeed, given that the only difference between the two scales relevant to their performance as a measure of Theta is that Scale VW has slightly greater validity, we would if forced to choose, select Scale VW as a measure of Theta over Scale XY. Similarly, we see no reason why, if one wishes to measure the causal influence reflected as the general self-monitoring factor, it is wrong to use a measure that includes items from both the social stage presence factor and the other-directed self-presentation factor (as well as those from the expressive self-control factor)-despite the fact that the factors correlate differently with other variables largely unrelated to the general factor. All of the objections we raised with respect to Scale VW have been raised or implied, in some form, concerning the Self-Monitoring Scale. And, the answers one can offer in defense of Scale VW can analogously be applied to the use of the Self-Monitoring Scale.

But we would now like to ponder one further objection to including items from both the social stage presence and the other-directed self-presentation factors on the same measure. These two factors (unlike the other two possible pairs of the three factors) correlate very minimally. In a large sample these two factors correlated but 05 (Gangestad \& Snyder, 1985b). Given that they correlate so minimally, how can these nearly orthogonal factors be causally related? And how is it that they can be summed (together with other items) to measure some common factor? At this point, it is instructive to reconsider the correlation that exists between V and W in Scale VW. We know that this scale, as a measure of Theta, has a validity coefficient of .64. Yet the components of the scale, $V$ and $W$, correlate zero. Of course, the reason that $\mathrm{V}$ and $\mathrm{W}$ correlate zero is not that they share no causal influences. Rather, it is because they share two causal influences, one influencing them similarly, the other influencing them in opposite ways. In our view, the reason that the factors of social stage presence and other-directed self-presentation correlate minimally is because they similarly have multiple shared influences. On the one hand, we have argued, they are both influenced by the causal factor that is reflected as the general factor. On the other hand, they each reflect social self-confidence and self-esteem (variables largely orthogonal to the general self-monitoring factor), but in opposite directions. Summing items from each factor (together with additional items) yields a measure correlated more highly than either factor with the general factor, but only modestly with social selfconfidence or self-esteem.

\section{Commentary on Factor Analysis and Measurement}

We would now like to comment generally on the strategies that guide psychometric scale construction and evaluation. It seems to us that implicit in the concerns expressed about the Self-Monitoring Scale is an assumption, the assumption that the development and evaluation of scales is not terribly difficult if one follows simple, invariant recipes. Thus, Briggs and Cheek (1986) recently recommended three simple rules to be followed to refine measurement of constructs: (a) A single scale should measure a single construct; (b) components of a scale should be treated as separate constructs if they are differentially related to other measures; and (c) factor analysis should be applied routinely to new personality scales.

Although each of these rules surely has proper applicability in many contexts, rigid adherence to them may ignore the complexities of explicating individual differences. We have already illustrated how two components can sum to validly measure a latent causal factor, and yet correlate differently with a second factor and not at all with each other (a situation that the second rule would find problematic). But what of the prescription that factor analysis be applied to all new measures? We see nothing inherently wrong with such applications. Surely, factor analysis can tell a great deal about a measure's internal structure. Nevertheless, what one should make of the factor structure may be problematic. Although Briggs and Cheek (1986) recognized the indeterminacy of factor rotation (cf. Lykken, 1971), they nevertheless appear to accept the primacy of the simple structure factors when they stated that a measure of the general factor underlying the Self-Monitoring Scale is not adequate "because

\footnotetext{
${ }^{3}$ McKinley and Hathaway (1940) made a similar point concerning the addition of a suppressor key $\left(C_{H}\right)$ onto a Minnesota Multiphasic Personality Inventory (MMPI) scale $(\mathbf{H}=$ hypochondriasis): "Although we do not hold that two persons are alike whose $\mathrm{H}-\mathrm{C}_{\mathrm{H}}$ scores are both 20 , the one with $\mathrm{H}=20$ and $\mathrm{C}_{\mathrm{H}}=0$, the other with $\mathrm{H}=40$ and $\mathrm{C}_{\mathrm{H}}=$ 20 , we have been unable to find any difference between them related to hypochondriasis" (p. 262). Of course, the fact that the addition of a suppressor key can increase the validity of a scale and the fact that $V$ and $W$ can sum to create a highly valid measure of Theta, more valid than Scale XY (despite lower validities of the components), exist for the same reason: Each occurs because systematic nuisance variance in the components cancels, and thus is not reflected, in total score variance.
} 
it does not articulate the multiple dimensions inherent in the scale" (p. 129).

Alternatives to simple structure rotation have been suggested as appropriate in certain circumstances. Thus, Meehl (1972) suggested that when there exists ample evidence that genetic contribution underlies a personality variable, one criterion for factor placement might be the genetic loading of the factor. That factor with the highest genetic loading might then serve as a guide for scale construction. Because of difficulties with heritability coefficients, we do not know if the general factor of the Self-Monitoring Scale maximizes the genetic loading. Nevertheless, we can reasonably infer that the general factor is in the near vicinity of the genetic maxima; thus, at least part of our rationale for choosing to interpret the measure in light of the general factor is identical to the rationale underlying Meehl's recommendation. ${ }^{4}$

Of course, one may claim that by informally using genetic loading to guide interpretation of the Self-Monitoring Scale, we adopt a measurement criterion that is not clearly defined. Indeed, although we have evidence that some causal influence underlies the general factor, it is quite true that we do not yet understand precisely the nature of that influence. Thus, if the influence is genetic in nature, just what is the genetic influence? We are currently in no position to answer that question definitely. And isn't this situation-having a measure of something, but not knowing precisely what the something is-at odds with the fundamental rationale behind measurement?

There was a time when the accepted answer to this question would have been yes. But no longer can one make such a claim about scientific measurement. Indeed, it is now a commonplace observation within the philosophy of science that theoretical terms and targets of measurement schemes are often, for long periods of time, understood in only vague or even flawed terms. As one philosopher put it,

\begin{abstract}
Gone are the days when righteous philosophers could puff indignantly at the unhygienic practice of not defining the key terms of a new theory. We know all too well that rigorous and exact definitions come relatively late in the development of the sciences, that they are often proceeded by a period in which theoretical language is put to work with highly flawed views about the objects to which it is intended to apply. During this period scientists may yearn for relief from the obscurity into which their linguistic practices lead them. They struggle along, however, . . trying, in a piecemeal way, to make their statements more exact, so that they will at last know what they are talking about. (Kitcher, 1985, pp. 342-343)
\end{abstract}

Precisely this recognition that scientific understanding can and does progress despite imprecise explication of terms provided, to a substantial extent, the impetus for Cronbach and Meehl (1955) to explicate the notion of construct validity. Indeed, it is too uncommonly appreciated or remembered that Cronbach and Meehl's classic article fundamentally advocates the explicit acceptance of imperfect or even flawed understandings of measured individual differences. Of course, one does not want to tolerate imprecision indefinitely. Thus through recognition of the imprecision, one forms hunches about the more exact nature of the individual differences and through research implementing the imprecise measure, one attempts to validate those more exact understandings.

In sum, successful explication of important influences on the development and expression of personality may not be guaran- teed by rigid adherence to simple recipes. Rather, given the broad indeterminacy of many psychometric relations vis-à-vis the real causal world, the identification and explication of important influences is still dependent, to a significant extent, on successful hunches and even guesswork. We have developed a perspective regarding the influences underlying the Self-Monitoring Scale, one built on a series of theoretical hunches. And now there is a body of data supporting that perspective. But the perspective is not yet complete; further hunches are needed (and are being developed) to more precisely explicate the nature of the influences. These hunches should be allowed to succeed or fail on the basis of empirical data that is truly relevant to their worth, and not on the basis of a priori solutions to indeterminate psychometric issues.

\section{Self-Monitoring: Validity of the Interpretation}

We began with the observation that the Self-Monitoring Scale empirically works. A large number of associations exist between the measure and criterion variables. After examination of data, we offered a view that a major reason why the measure works is that it validly taps a unitary causal influence that, as reanalyses indicate, is implicated in many domains of social behavior. This causal influence, clearly evidenced in family data, accounts for as much as $60 \%$ of the reliable variance in full scale scores (in a college population), a substantial amount. Still, there do exist sources of total score variance independent of the major contributor, and as we noted, these minor sources may sometimes account for moderate relations of the Self-Monitoring Scale. Analyses of the rotated factors, in addition to the full scale, should help determine the relative contributions of these sources of variance. The fact that the rotated factors may correlate differently with variables not highly related to the total scale is largely a red herring in the evaluation of the total scale as a measure of some influence tapped by all three factors. Similarly, the fact that two factors correlate near zero does not necessarily mean that they are not, in part, reflections of a common influence.

Thus far, however, we have discussed only what Loevinger (1957) referred to as the intrinsic validity of the measure. The intrinsic validity of a measure is the extent to which the measure taps something that is systematic and meaningful. Evaluation of whether or not a measure taps something implicates the kinds of empirical and methodological considerations we have discussed: empirical relations, family data, psychometrics, and so forth. To a considerable (although not full) extent, evaluation of intrinsic validity is substantially atheoretical.

As Loevinger (1957) also discussed, however, there is another side to construct validity, a side that is largely theoretical. Specifically, once one has decided that a measure does tap something systematic and meaningful, one can then evaluate the extent to which the meaning that any theoretical interpretation assigns to what the measure taps is the correct meaning. In Loevinger's (1957) terms, one can assess the validity of the interpretation. In the context of assessing the construct validity of the

\footnotetext{
${ }^{4}$ In fact, the genetic maxima appears to be very close to the first rotated factor yielded by an analysis of the monozygotic (MZ) cross-twin correlations (see Footnote 2). The MZ correlation on this factor was .69 ; the dizygotic (DZ) correlation was .19.
} 
Self-Monitoring Scale, one may ask, what is the validity of the interpretation of the Self-Monitoring Scale entailed by the selfmonitoring construct? That is, is the something we claim is reflected as the general factor underlying the Self-Monitoring Scale properly interpreted by the construct of self-monitoring?

Although it may seem that this question should be one straightforwardly answered, in fact it is not even one that is straightforwardly understandable. Much has been said about self-monitoring since the construct was first introduced. What precisely, out of all that has been said, constitutes the self-monitoring construct? Just the initial characterization? It hardly seems right that the construct should be identified solely with the initial statements, given that the theory concerning the individual differences tapped by the Self-Monitoring Scale has evolved through extension, elaboration, and reemphasis. But this being so, how much extension, elaboration, and reemphasis can occur before the construct is, in fact, no longer the same construct? Perhaps, we might answer, there is a set of core propositions that are fundamental to the construct and, if one adopts an interpretation that no longer embodies these core propositions, the interpretation is no longer the self-monitoring construct. If so, what are the core propositions? and how does one decide what are the core propositions?

This line of meta-theoretical questioning may be a meaningful-even if a difficult-one, and clearly we must provide answers to it before answering the question about the validity of the self-monitoring construct. In the end, however, what is important is that we provide a correct account of the individual differences underlying the Self-Monitoring Scale, and not the truth of the self-monitoring construct (whatever we might decide it really is at heart). Thus, we would prefer to not directly address whether the self-monitoring construct is "right," but instead to ask, "What is true about the individual differences underlying the Self-Monitoring Scale?" Nevertheless, we understand that some of the concerns that have been expressed about the Self-Monitoring Scale are concerns about the validity of the self-monitoring formulation. And, given that those so concerned have very often expressed it in the context of whether the full scale taps attitude-behavior consistency, cross-situational variability, and sensitivity to facial cues of emotion, it is clear that these researchers identify the self-monitoring formulation with the initial statements about self-monitoring. For our discussion, we adopt this convention.

At least in one sense, the initial statements concerning selfmonitoring may fall short of successfully explicating the nature of the latent causal influence underlying the Self-Monitoring Scale, in light of what we now understand about that influence. It appears that what is common to the majority of items on the scale and accounts for major relations between the scale and external variables is a causal influence substantially genetic in nature. This fact was not anticipated by the initial statements about self-monitoring. Of course, we would hardly expect it to have been anticipated, given that the initial statements concerned proximal psychological individual differences, whereas the genetic factor is distal and biological in nature. In any case, given that the self-monitoring formulation does concern the proximal rather than the distal level of explication, the genetic explication poses no direct rival to the self-monitoring formulation. Rather, in light of newer findings, we may ask, does the self-monitoring construct successfully explicate the proximal psychological individual differences influenced, through a course of development, by the causal variable underlying the Self-Monitoring Scale?

A large number of empirical investigations have provided support for a wide-ranging set of hypotheses about the involvement of self-monitoring in diverse domains of cognitive, behavioral, and interpersonal functioning, including hypotheses directly derived from the initial statements concerning self-monitoring (for reviews, see Snyder, 1979, in press; Shaw \& Costanzo, 1982). At the same time as findings consistent with the self-monitoring formulation have accumulated, there clearly have been some failures to confirm hypotheses derived from the self-monitoring construct (e.g., Arkin, Gabrenya, Appelman, \& Cochran, 1979; Cheek, 1982; Santee \& Maslach, 1982; Schneiderman, 1980; Wolfe, Lennox, \& Hudiburg, 1983; Zanna et al., 1980; Zuckerman \& Reis, 1978). Of course, given the known effects of sampling variability, occasional failures to confirm hypotheses in specific samples must be expected even when genuine effects exist in the general population. Thus, for instance, consider the study reported by Zuckerman and Reis (1978). They report a correlation between attitude and behavior for low self-monitoring individuals of .47 and for high self-monitoring individuals of .24. This difference was not statistically significant in their study $(z=1.47, p<.15$ ), and some have claimed, on this basis, that this study represents a failure of the self-monitoring construct (e.g., Lennox \& Wolfe, 1984). Clearly, however, the effect Zuckerman and Reis (1978) report is in the predicted direction and-in light of the many studies that have found significant predicted effects of self-monitoring on the attitude-behavior relation (for a review, see Snyder, 1982)-surely does not represent a strong refutation.

Furthermore, some of the results that investigators have called failures may, from our perspective, only falsify ill-taken hypotheses that cannot be straightforwardly derived from the self-monitoring construct. As illustrative, consider the study by Santee and Maslach (1982) and how its results are characterized by others. Santee and Maslach found that the Self-Monitoring Scale did not correlate with amount of conformity in group discussion sessions, and Lennox and Wolfe (1984) cite this result as a failure of the construct. The Self-Monitoring Scale, however, was never intended to be a measure of conformity and, according to the construct of self-monitoring, should relate to conformity only in social contexts in which normative climates specify conformity as the situationally appropriate presentation of self (e.g., Snyder \& Monson, 1975). In fact, the authors of this study themselves noted that it is "possible that the normative cues to which the high self-monitor attends were weak or ambiguous" in their experiment (Santee \& Maslach, 1982, p. 699; see also in Snyder, 1974, the correlation of the Self-Monitoring Scale with the $c$ scale of Ring \& Wallston's, 1968, Performance Style Test, a measure that was constructed to tap conformity-it is low and slightly negative).

Finally, even hypotheses that can reasonably be derived from the self-monitoring formulation may fail to receive support in specific studies, despite their being true, due to faulty auxiliary assumptions involved in the empirical tests. For instance, we may examine the study by Wolfe, Lennox, and Hudiburg (1983). These investigators intended to assess the hypothesis that the alcohol and marijuana usage of low self-monitoring individuals should be predictable from dispositional factors, and 
that of high self-monitoring individuals should be predictable from environmental factors. To test this hypothesis, they first factor analyzed a large set of variables, extracting two factors that they interpreted as a dispositional factor and an environmental one. Clearly, for this analysis to provide a fair test of the hypothesis, the auxiliary assumption that the two factors do indeed tap dispositional factors and environmental pressures related to alcohol and marijuana usage, must be correct. An examination of the variables that load on each of these two factors, however, reveals that this assumption is extremely doubtful. The factor they interpret as a dispositional factor appears, to a large extent, to reflect self-esteem. And, four of the five variables that load at least .3 on what they call an environmental factor (excluding self-monitoring itself) are drug-specific positive attitudes, drug-specific negative attitudes (loading negatively), sex, and religiosity (loading negatively) - all variables that clearly reflect dispositional, personal entities more directly than features of the environment. The fact that the Self-Monitoring Scale did not moderate the extent to which these two factors were related to drug usage, then, tells us little to nothing about the truth of the hypothesis these authors intended to test.

Nevertheless, some of the failures of the self-monitoring formulation are surely not due to sampling variability, ill-taken hypotheses, or faulty auxiliary assumptions. We fully expect some specific, well-formulated hypotheses to be reliably and consistently disconfirmable in carefully conducted studies. Furthermore (as we have already noted) we fully expect some specific relations of the Self-Monitoring Scale to be attributable to one or another individual rotated factor and not to the general self-monitoring factor. At the present time, we do not know the nature of these specific hypotheses and relations. Indeed, we believe that the currently available evidence does not yet permit one to provide definite and definitive conclusions about which hypotheses have or have not been reliably and consistently disconfirmed and about the implications of such outcomes. Rather than attempt to review this evidence-an endeavor that may yet be premature-we wish to offer some suggestions that we hope will lead to a more effective evaluation of the validity of the interpretation entailed by the self-monitoring construct andas we have stated-most importantly, to a better understanding of the individual differences that do underlie the Self-Monitoring Scale.

First, any demonstrably reliable and consistent disconfirmations of hypotheses clearly signal gaps between the interpretation of the differences underlying the Self-Monitoring Scale entailed by the current construct and the true nature of these differences. In the assessment of hypotheses that are initially disconfirmed, the same standards of reliability and consistency should be applied as those applied in the assessment of hypotheses that are initially corroborated. That is, just as corroborating results should be demonstrably reliable through replication, so should disconfirming results be replicated. To the extent that disconfirming results are systematically replicated, we can be confident that the initial disconfirmation is not attributable to either sampling variability or faulty auxiliary assumptions (cf. Carlsmith, Ellsworth, \& Aronson, 1976).

Once reliable and consistent disconfirmations have been demonstrated, researchers may assess where in the network of propositions constituting the self-monitoring formulation there may exist gaps or falsehoods. Although the self-monitoring for- mulation can be represented as a network of propositions connected to one another through common terms, and although certain entailments may exist within the network, the propositions do not all entail one another. As a result, the formulation may be close to the truth, in the sense that most of its propositions are true, and yet the formulation may still yield false hypotheses. Indeed, even a single false proposition within the network is sufficient to produce false hypotheses. Thus, falsified hypotheses do not necessitate the falsehood of the entire construct. They necessitate only that some portion of it is false. It is not particularly informative to know that some aspect is false. What we wish to know is where the construct is false-the proposition, or set of propositions, within the formulation that is false.

Finally, once problematic propositions within the formulation have been located, attempts to alter the formulation to account for disconfirming evidence may be undertaken. In the case of the most minimal alteration, it may be that a change in a single proposition is sufficient to account for anomalous results. At the other extreme, it may be that problematic results cannot be readily accounted for without a recasting of the entire formulation. Depending on one's philosophy of science, one may believe that knowledge is most effectively advanced through attempts to retain as much of the initial core of the formulation as possible (cf. Lakatos, 1970), or one may believe that the scientific enterprise is served best by relentless attempts to provide radically different alternative accounts (cf. Feyerabend, 1981).

Within the framework of either strategy, any attempted reformulation must not ignore the accumulated body of confirmatory evidence, in addition to accounting for the anomalous results. Of course, as the total body of evidence, both confirmatory and disconfirmatory, accumulates, it will become increasingly difficult to account for all of the evidence. Thus, a consideration of effect sizes may play an increasingly important role in guiding the interpretation of the latent entity underlying the Self-Monitoring Scale. That is, one may ensure that one's formulation can account effectively for the largest relations the Self-Monitoring Scale possesses with external criterion variables, even if it cannot account fully for relations that, although found to be statistically significant in specific studies, are ones of relatively modest effect size.

Signs of the first step of this process of evaluation and reformulation are beginning to appear. As we have already noted, disconfirmations of hypotheses derived from the self-monitoring formulation have been reported in the published literature. We anticipate that any such demonstrations that are reliable and consistent will indicate where, within the self-monitoring formulation, there may exist problematic propositions.

As a final comment, we emphasize that the issue of whether or not the current self-monitoring formulation provides the correct interpretation is quite a separate issue from whether or not the scale measures something systematic and meaningful. We have presented what we believe is a strong case that some major causal influence is responsible for generating many substantial relations between the measure and external variables. Whether the correct causal interpretation of these relations looks very much like the current self-monitoring formulation or looks very different from it, there is no reason to believe that it cannot be understood through an examina- 
tion of empirical relations. Any assertion of the form, "it is impossible to determine what the [Self-Monitoring] scale might be measuring" (Lennox \& Wolfe, 1984, p. 1350), is very probably false, and such statements can only be counterproductive in attempts to better understand self-monitoring phenomena.

\section{Means of Assessment: How Should Self-Monitoring Be Measured?}

The process of evolution in theory and research on self-monitoring represents a specific exemplar of a more general approach to employing a measure of individual differences as a vehicle for developing psychological theory. To use a measure for these purposes, one must first admit that although one has some ideas about what the measure taps, one doesn't really know for sure. Indeed, one may never know precisely what it measures. One hopes, however, that the interpretations and elaborations offered over time get closer and closer to the truth (cf. Cronbach \& Meehl, 1955; Loevinger, 1957).

Nevertheless, we recognize that it may be possible to construct a better measure of what underlies the Self-Monitoring Scale. In fact, Lennox and Wolfe (1984) have attempted to construct what they regard as a "more adequate measure" ( $p$. 1350 ), one that better captures the spirit of the self-monitoring construct as they construe it. Before we note several concerns about the 13-item Lennox and Wolfe (1984) measure as an improvement over the original Self-Monitoring Scale, however, we ask a fundamental question concerning the two measures: How much difference is there between them? To address this question (which Lennox and Wolfe never addressed), we administered both the Self-Monitoring Scale and the Lennox and Wolfe measure to 313 University of Minnesota undergraduates, as part of a larger questionnaire session. The resultant correlation between the two measures was .52. Correcting this correlation for attenuation due to unreliability of the measures yields an estimated correlation of .72. It appears, then, that the two measures share more than $50 \%$ of their reliable variance-a substantial figure.

\section{Evaluating the Intrinsic Validity of Alternative Measures}

In a comparison of the two measures, then, the major question becomes this one: of the $50 \%$ reliable variance not shared by the measures, which variation contains more intrinsic validity-the $50 \%$ reliable variance of the Self-Monitoring Scale not shared with the Lennox and Wolfe measure, or the $50 \%$ reliable variance in the Lennox and Wolfe (1984) measure not shared with the Self-Monitoring Scale? Although we are not prepared to cast a final verdict, there are reasons to believe that at least a portion of the $50 \%$ variance in the Lennox and Wolfe measure not shared with the Self-Monitoring Scale is not intrinsically valid variance, and thus will not covary with important criterion features of social behavior.

First, Lennox and Wolfe (1984) chose to construct their measure very narrowly. Many of their items are, in terms of explicit content, virtual restatements of one another (e.g., "I have found that I can adjust my behavior to meet the requirements of any situation I find myself in" and "Once I know what the situation calls for, it's easy for me to regulate my actions accordingly"). Including literal restatements in a measure will, of course, result in greater reliability of the measure (the internal consistency of the Lennox and Wolfe measure is .75 ; that of the original Self-Monitoring Scale, .66; Gangestad $\&$ Snyder, 1985b). Much of the increment in reliability, however, will not be attributable to validity. For the error component that exists in the responses to the first item will be expected to correlate with the error component that exists in the responses to the second item (that is, the items will be expected to be redundant signs of the underlying structure; e.g., Meehl \& Golden, 1982). Given that the Lennox and Wolfe measure includes several items with very similar explicit content, we must expect that much of the covariation between items that contributes to the reliability of the measure is not attributable to a latent causal factor and, instead, is attributable to correlated error components.

Second, there exists good reason to believe that some of the reliable variance in the Lennox and Wolfe measure is attributable to response bias. Eleven of the 13 items on their measure are keyed in the same direction; only 2 items are keyed in the other direction. Although it may be that when a true-false response format is used on an unbalanced test, total score variance attributable to response bias is minimal (e.g., Rorer, 1965), it is doubtful that when a six-point format is used (as Lennox and Wolfe did), response bias will be similarly minimal (e.g., Nunnally, 1967; cf. Cronbach, 1955). For when a six-point format is used, not only will variation in respondents' tendencies to acquiesce be reflected in total score variance, but also most any variation in respondents' usage of the response scale will be reflected in total score variance. Thus, for instance, variation in respondents' tendencies to use the extremes of the scales will be a source of response bias.

Third, although many of the Lennox and Wolfe items are face valid, we believe that many of their items are not well written. Conventional wisdom on the construction of personality tests advises that items be clear, concise, unambiguous, and written in terms easily understandable by the respondent (Jackson, 1971). Most of the items on the Lennox and Wolfe measure, in contrast, are long, and many contain terms the average respondent would not use in the context in which the terms are presented. Thus, average respondents, whether high or low in self-monitoring, would not say that they regulate their actions. Similarly, few people would spontaneously claim that they adjust or alter their behavior. To the extent that there do exist systematic factors (such as vocabulary size) orthogonal to selfmonitoring that influence acceptance of these terms when they are applied to behavior, however, there will exist reliable (although undesirable) variance in the total scale scores that is orthogonal to self-monitoring.

These three considerations may pose threats to the intrinsic validity of the Lennox and Wolfe (1984) measure. What, then, are the relative intrinsic validities of the Lennox and Wolfe measure and the Self-Monitoring Scale? Although further empirical research is needed before a final answer to this question can be provided, we can at this time report evidence that may permit a provisional answer. We estimate that the Self-Monitoring Scale correlates approximately +.65 with the latent causal influence postulated to account for many relations of the measure with important social variables (Gangestad \& Snyder, 1985b). In comparison, we estimate that the Lennox and Wolfe 
Table 2

Eighteen-Item Measure of Self-Monitoring

\begin{tabular}{|c|c|}
\hline Item no. & Item \\
\hline 1. & I find it hard to imitate the behavior of other people. (F)(.39) \\
\hline 2. & At parties and social gatherings, I do not attempt to do or say things that others will like. $(\mathrm{F})(.20)$ \\
\hline 3. & I can only argue for ideas which I already believe. $(F)(.24)$ \\
\hline 4. & I can make impromptu speeches even on topics about which I have almost no information. $(T)(.39)$ \\
\hline 5. & I guess I put on a show to impress or entertain others. $(T)(.48)$ \\
\hline 6. & I would probably make a good actor. (T)(.59) \\
\hline 7. & In a group of people I am rarely the center of attention. $(F)(.45)$ \\
\hline 8. & In different situations and with different people, I often act like very different persons. $(T)(.25)$ \\
\hline 9. & I am not particularly good at making other people like me. (F)(.28) \\
\hline 10. & I'm not always the person I appear to be. (T)(.22) \\
\hline 11. & I would not change my opinions (or the way I do things) in order to please someone or win their favor. (F)(.17) \\
\hline 12. & I have considered being an entertainer. $(\mathrm{T})(.41)$ \\
\hline 13. & I have never been good at games like charades or improvisational acting. (F)(.49) \\
\hline 14. & I have trouble changing my behavior to suit different people and different situations. $(F)(.34)$ \\
\hline 15. & At a party I let others keep the jokes and stories going. (F)(.45) \\
\hline 16. & I feel a bit awkward in public and do not show up quite as well as I should. $(F)(.31)$ \\
\hline 17. & I can look anyone in the eye and tell a lie with a straight face (if for a right end). (T)(.30) \\
\hline 18. & I may deceive people by being friendly when I really dislike them. (T)(.18) \\
\hline
\end{tabular}

Note. Keying is given by either $\mathrm{T}$ (true) or $\mathrm{F}$ (false) in parentheses following item. High self-monitoring individuals tend to answer in the keyed direction; low self-monitoring individuals tend to answer in the alternative direction. Item loading on first unrotated factor is given in second set of parentheses.

measure correlates only approximately +.4 with this latent influence. ${ }^{5}$

\section{A New Eighteen-Item Measure of Self-Monitoring}

Of course, if we can measure the same latent influence as the Self-Monitoring Scale taps with a measure possessing equal intrinsic validity but higher reliability, we should want to do so. In fact, we do believe that it is possible to increase the reliability of the Self-Monitoring Scale and, at the same time, retain its established intrinsic validity. Latent structure analyses of the Self-Monitoring Scale have indicated that a few self-monitoring items discriminate between the latent classes of high self-monitoring and low self-monitoring individuals poorly (Gangestad \& Snyder, 1985b). Given that our reanalyses of self-monitoring studies demonstrate that this latent factor accounts for most of the covariation between the Self-Monitoring Scale and the external criterion variables in these studies, we have recommended that these items be dropped from the measure of selfmonitoring. Our new, 18-item measure of self-monitoring, consisting only of those items correlating at least +.15 with the latent self-monitoring causal variable (as estimated by loadings on the first unrotated factor), is presented in Table 2.

This new measure of self-monitoring has an internal consistency (coefficient alpha) of +.70 , higher than that of the original 25-item measure. Moreover, this new measure is more factorially pure than the original measure. The first unrotated factor emerging from a principal-axes factor analysis accounts for $62 \%$ of the common variance (with three factors extracted), compared to $51 \%$ accounted for by the first unrotated factor emerging from a factor analysis of the original 25-item measure. More important, total scale scores for the new 18-item measure are uncorrelated with an estimate of the second, relatively minor, source of variation, $r=+.03$. By contrast, total scale scores on the original 25 -item measures are mildly correlated with an estimate of the second source of variation, $r=+.15$. For further information on this new measure, as well as guidelines for its use, see Gangestad and Snyder (1985b).

Of course, it will someday be possible to construct an even better measure, one that possesses even greater intrinsic validity. To most effectively do so requires the identification of new content domains that tap the latent causal influence that underlies the current measure. Thus, identification of these new content domains will follow from yet more research in which the current measure works (cf. Cronbach \& Meehl, 1955, on bootstraps effects). From this perspective, when a better measure comes along, it will not be because the current measure does not possess intrinsic validity. To the contrary, the better measure will have come into being because the intrinsic validity of the current measure has produced an increased understanding of the nature of important individual differences in social behavior.

\footnotetext{
${ }^{5}$ Just as we recognize that the three rotated factors of the Self-Monitoring Scale may possess meaningful relations with behavioral variables independently of the major causal variable underlying the Self-Monitoring Scale, we recognize that the Lennox and Wolfe (1984) measure too may possess such relations. Thus, the Lennox and Wolfe measure may correlate with some subset of external criterion variables more highly than does the Self-Monitoring Scale.
}

\section{References}

Arkin, R. M., Gabrenya, W. K., Jr., Appelman, S. S., \& Cochran, S. T. (1979). Self-presentation, self-monitoring, and self-serving bias in causal attribution. Personality and Social Psychology Bulletin, 5, 7376.

Ajzen, I., Timko, C., \& White, J. B. (1982). Self-monitoring and the attitude-behavior relation. Journal of Personality and Social Psychology, 43, 426-435.

Becherer, R. C., \& Richard, L. M. (1978). Self-monitoring as a modera- 
tor of consumer behavior. Journal of Consumer Research, 5, 159162.

Briggs, S. R., \& Cheek, J. M. (1986). The role of factor analysis in the development and evaluation of personality scales. Journal of Personality, 54, 106-148.

Briggs, S. R., Cheek, J. M., \& Buss, A. H. (1980). An analysis of the Self-Monitoring Scale. Journal of Personality and Social Psychology; 38, 679-686.

Caldwell, D. F., \& O'Reilly, C. A. (1982). Responses to failure: The effects of choice and responsibility on impression management. Academy of Management Journal, 25, 121-136.

Carlsmith, J. M., Ellsworth, P. C., \& Aronson, E. (1976). Methods of research in social psychology. Reading, MA: Addison-Wesley.

Cattell, R. B. (1966). The scree test for the number of factors. Multivariate Behavioral Research, 1, 140-160.

Cattell, R. B. (1978). The scientific use of factor analysis in behavioral and life sciences. New York: Plenum Press.

Cheek, J. M. (1982). Aggregation, moderator variables, and the validity of personality tests: A peer-rating study. Journal of Personality and Social Psychology, 43, 1254-1269.

Cheek, J. M., \& Briggs, S. R. (1981, August). Self-consciousness, selfmonitoring, and aspects of identity. Paper presented at the meeting of the American Psychological Association, Los Angeles, CA.

Cronbach, L. J. (1955). Processes affecting scores on "understanding of others" and "assumed similarity." Psychological Bulletin, 52, 177 193.

Cronbach, L. J., \& Meehl, P. E. (1955). Construct validity in psychological tests. Psychological Bulletin, 52, 281-302.

Danheiser, P. R., \& Graziano, W. G. (1982). Self-monitoring and cooperation as a self-presentational strategy. Journal of Personality and Social Psychology, 42, 497-505.

Dworkin, R. H. (1977, August). Genetic influences on cross-situational consistency. Paper presented at the Second International Congress on Twin Studies, Washington, DC.

Eysenck, H. J. (1950). Criterion analysis--An application of the hypothetico-deductive method of factor analysis. Psychological Review, $57,38-53$.

Feyerabend, P. K. (1981). Realism, rationalism, and scientific method: Philosophical papers (Vol. 1). Cambridge, England: Cambridge University Press.

Furnham, A., \& Capon, M. (1983). Social skills and self-monitoring processes. Personality and Individual Differences, 4, 171-178.

Gabrenya, W. K., Jr., \& Arkin, R. M. (1980). Factor structure and factor correlates of the Self-Monitoring Scale. Personality and Social Psychology Bulletin, 6, 13-22.

Gangestad, S. (1984). On the etiology of individual differences in selfmonitoring and expressive self-control: Testing the case of strong genetic influence. Unpublished doctoral dissertation, University of Minnesota.

Gangestad, S. (1985). Behavior-genetic analyses of the Self-Monitoring Scale. Unpublished research. University of Minnesota.

Gangestad, S., \& Snyder, M. (1985a). On the nature of self-monitoring: An examination of latent causal structure. In P. Shaver (Ed.), Review of personality and social psychology (Vol. 6, pp. 65-85). Beverly Hills, CA: Sage.

Gangestad, S., \& Snyder, M. (1985b). To carve nature at its joints: On the existence of discrete classes in personality. Psychological Review 92, 317-349.

Guilford, J. P., \& Zimmerman, W. S. (1963). Some variable-sampling problems in the rotation of axes in factor analysis. Psychological Bulletin, 60, 289-301.

Hays, W. L. (1981). Statistics (3rd ed.). New York: Holt, Rinehart \& Winston.

Ickes, W. J., Layden, M. A., \& Barnes, R. D. (1978). Objective selfawareness and individuation: An empirical link. Journal of Personal$i t y, 46,146-161$.
Jackson, D. N. (1967). Personality Research Form manual. New York: Research Psychologists Press.

Jackson, D. N. (1971). Structured personality tests: 1971. Psychological Review, 78, 229-248.

Kitcher, P. (1985). Vaulting ambition: Sociobiology and the quest for human nature. Cambridge, MA: MIT Press.

Krauss, R. M., Geller, V., \& Olson, C. (1976, September). Modalities and cues in perceiving deception. Paper presented at the meeting of the American Psychological Association, Washington, DC.

Kulik, J. A., \& Taylor, S. E. (1981). Self-monitoring and the use of consensus information. Journal of Personality, 49, 75-84.

Lakatos, I. (1970). Falsification and the methodology of scientific research programmes. In 1. Lakatos \& A. Musgrave (Eds.), Criticism and the growth of knowledge (pp. 91-196). Cambridge, England: Cambridge University Press.

Lennox, R., \& Wolfe, R. (1984). Revision of the Self-Monitoring Scale. Journal of Personality and Social Psychology, 46, 1349-1364.

Lippa, R. (1976). Expressive control and the leakage of dispositional introversion-extraversion during role-played teaching. Journal of Personality, 46, 541-559.

Lippa, R. (1978). Expressive control, expressive consistency, and the correspondence between behavior and personality. Journal of Personality, 46, 438-461.

Loevinger, J. (1957). Objective tests as instruments of psychological theory. Psychological Reports, 3, 635-694.

Lutsky, N., Woodworth, W., \& Clayton, S. (1980, May). Actions-attitudes-actions: A multivariate, longitudinal study of attitude-behavior consistency. Paper presented at the annual meeting of the Midwestern Psychological Association, St. Louis, MO.

Lykken, D. T. (1971). Multiple factor analysis and personality research. Journal of Experimental Research in Personality, 5, 161-170.

McCann, D., \& Hancock, R. D. (1983). Self-monitoring in communicative interactions: Social cognitive consequences of goal-directed message modification. Journal of Experimental Social Psychology, 19, 109-121.

McKinley, J. C., \& Hathaway, S. R. (1940). A multiphasic personality schedule: II. A differential study of hypochondriasis. Journal of Psychology, 10, 255-268.

McNemar, Q. (1946). Opinion-attitude methodology. Psychological Bulletin, 43, 289-374.

Meehl, P. E. (1972). Reactions, reflections, projections. In J. Butcher (Ed.), Objective personality assessment: Changing perspectives (pp. 131-189). New York: Academic Press.

Meehl, P. E., \& Golden, R. R. (1982). Taxometric methods. In J. N. Butcher \& P. C. Kendall (Eds.), The handbook of research methods in clinical psychology (pp. 127-181). New York: Wiley.

Nowack, W., \& Kammer, D. (1984). Towards a reconceptualization of self-monitoring. Unpublished manuscript, University of Bielefeld, Bielefeld, FRG.

Nunnally, J. C. (1967). Psychometric theory. New York: McGraw-Hill. Overall, J. (1964). Note on the scientific status of factors. Psychological Bulletin, 61, 270-276.

Paulhus, D. (1982). Individual differences, self-perception, and cognitive dissonance: Their concurrent operation in forced compliance. Journal of Personality and Social Psychology, 43, 838-852.

Penner, L. A., \& Wymer, W. E. (1983). The moderator approach to behavioral predictability: Some of the variables some of the time. Journal of Research in Personality, 17, 339-353.

Rarick, D. L., Soldow, G. F., \& Geizer, R. S. (1976). Self-monitoring as a mediator of conformity. Central States Speech Journal, 27, 267271.

Riggio, R. E., \& Friedman, H. S. (1982). The interrelationships of selfmonitoring factors, personality traits, and nonverbal social skills. Journal of Nonverbal Behavior, 7, 33-45.

Riggio, R. E., \& Friedman, H. S. (1983). Individual differences and cues 
to deception. Journal of Personality and Social Psychology, 45, 899915.

Ring, K., \& Wallston, K. (1968). A test to measure performance styles in interpersonal relations. Psychological Reports, 22, 147-154.

Rorer, L. G. (1965). The great response-style myth. Psychological Bulleiin, 63, 129-156.

Ross, M., McFarland, C., \& Fletcher, G. J. O. (1981). The effect of attitude on the recall of personal histories. Journal of Personality and Social Psychology, 40, 627-634.

Rummel, R. J. (1970), Applied factor analysis. Evanston, IL: Northwestern University Press.

Santee, R. T., \& Maslach, C. (1982). To agree or not to agree: Personal dissent amid pressure to conform. Journal of Personality and Social Psychology, 42, 690-700.

Schneiderman, W. (1980). A personality dimension of consistency versus variability without the use of self-reports or ratings. Journal of Personality and Social Psychology, 39, 158-164.

Shaffer, D. R., Smith, J. E., \& Tomarelli, M. (1982). Self-monitoring as a determinant of self-disclosure reciprocity during the acquaintance process. Journal of Personality and Social Psychology, 43, 163-175.

Shaw, M. E., \& Costanzo, P. R. (1982). Theories of social psychology (2nd ed.). New York: McGraw-Hill.

Siegman, A. W., \& Reynolds, M. A. (1983). Self-monitoring and speech in feigned and unfeigned lying. Journal of Personality and Social Psychology, 45, 1325-1333.

Snyder, M. (1974). Self-monitoring of expressive behavior. Journal of Personality and Social Psychology, 30, 526-537.

Snyder, M. (1979). Self-monitoring processes. In L. Berkowitz (Ed.), Advances in experimental social psychology (Vol. 12, pp. 85-128). New York; Academic Press.

Snyder, M. (1982). When believing means doing: Creating links between attitudes and behavior. In M. P. Zanna, C. P. Herman, \& E. T. Higgins (Eds.), Variability in social behavior: The Ontario Symposium (pp. 105-130). Hillsdale, NJ: Erlbaum.

Snyder, M. (in press). Public appearances/Private realities: The psychology of self-monitoring. New York: W. H. Freeman.

Snyder, M., Berscheid, E., \& Glick, P. (1985). Focusing on the exterior and the interior: Two investigations of the initiation of personal relationships. Journal of Personality and Social Psychology, 48, 14271439.

Snyder, M., Berscheid, E., \& Matwychuk, A. (1984). Unpublished research on personnel selection. University of Minnesota, Minneapolis.

Snyder, M., \& Cantor, N. (1980). Thinking about ourselves and others: Self-monitoring and social knowledge. Journal of Personality and Social Psychology, 39, 222-234.

Snyder, M., \& DeBono, K. G. (1985). Appeals to image and claims about quality: Understanding the psychology of advertising. Journal of Personality and Social Psychology, 49, 586-597.

Snyder, M., \& Gangestad, S. (1982). Choosing social situations: Two investigations of self-monitoring processes. Journal of Personality and Social Psychology, 43, 123-135.

Snyder, M., Gangestad, S., \& Simpson, J. A. (1983). Choosing friends as activity partners: The role of self-monitoring. Journal of Personality and Social Psychology, 45, 1061-1072.

Snyder, M., \& Kendzierski, D. (1982a). Acting on one's attitudes: Proce- dures for linking attitude and behavior. Journal of Experimental Social Psychology. 18, 165-183.

Snyder, M., \& Kendzierski, D. (1982b). Choosing social situations: A strategy for generating correspondence between attitudes and behavior. Journal of Personality, 50, 280-295.

Snyder, M., \& Monson, T. C. (1975). Persons, situations, and the control of social behavior. Journal of Personality and Social Psychology, 32, 637-644.

Snyder, M., \& Simpson, J. A. (1984). Self-monitoring and dating relationships. Journal of Personality and Social Psychology, 47, 12811291.

Snyder, M., \& Simpson, J. A. (1986). Orientations toward romantic relationships. In S. Duck \& D. Perlman (Eds.), Intimate relationships: Development, dynamics, and deterioration. Beverly Hills, CA: Sage.

Snyder, M., Simpson, J. A., \& Gangestad, S. (1986). Personality and sexual relations. Journal of Personality and Social Psychology, 51, 181-190.

Snyder, M., \& Smith, D. (1985, May). Self-monitoring and depression: Precipitating events and coping strategies. Paper presented at the annual meeting of the Midwestern Psychological Association, Chicago.

Snyder, M., \& Smith, D. (1986). Personality and friendship: The friendship worlds of self-monitoring. In V. Derlega \& B. Winstead (Eds.), Friendship and social interaction. New York: Springer-Verlag.

Snyder, M., \& Swann, W. B. (1976). When actions reflect attitudes: The politics of impression management. Journal of Personality and Social Psychology, 34, 1034-1042

Snyder, M., \& Tanke, E. D. (1976). Behavior and attitude: Some people are more consistent than others. Journal of Personality, 44, 510-517.

Sparacino, J., Ronchi, D., Bagley, T. K., Flesch, A. L., \& Kuhn, J. W. (1983). Self-monitoring and blood pressure. Journal of Personality and Social Psychology, 44, 365-375.

Sypher, B. D., \& Sypher, H. H. (1983). Self-monitoring and perceptions of communication ability in an organizational setting. Personality and Social Psychology Bulletin, 9, 297-304.

Thurstone, L. L. (1947). Multiple factor analysis. Chicago: University of Chicago Press.

Tobey, E. L., \& Tunnell, G. (1981). Predicting our impressions on others: Effects of public self-consciousness and acting, a self-monitoring subscale. Personality and Social Psychology Bulletin, 7, 661-669.

Tunnell, G. (1980). Intraindividual consistency in personality assessment: The effect of self-monitoring. Journal of Personality, 48, 220232.

Wolfe, R., Lennox, R., \& Hudiburg, R. (1983). Self-monitoring and sex as moderator variables in the statistical explanation of self-reported marijuana and alcohol use. Journal of Personality and Social Psychology, 44, 1069-1074.

Zanna, M. P., Olson, J. M., \& Fazio, R. H. (1980). Attitude-behavior consistency: An individual difference perspective. Journal of Personality and Social Psychology, 38, 432-440.

Zuckerman, M., \& Reis, H. T. (1978). A comparison of three models for predicting altruistic behavior. Journal of Personality and Social Psychology, 36, 498-510.

Received April 9, 1985

Revision received June 28, 1985 